\title{
The Vulnerability Problem of Business Ecosystems under Global Decoupling
}

\author{
Hongryol Cha \\ School of Business Administration \\ Kyungpook National University \\ 80 Daehak-ro, Buk-gu \\ Daegu, 41566, South Korea \\ Tel: +82 (053) 950-7403 \\ Email: hongryol.cha@knu.ac.kr
}

\author{
Jie $\mathrm{Wu} *$ \\ Chair Professor of Strategy and Entrepreneurship \\ University of Aberdeen Business School \\ King's College, Aberdeen AB24 5UA, United Kingdom \\ Phone: +4407882528835 \\ Email: jie.wu@abdn.ac.uk
}

\begin{abstract}
Masaaki Kotabe
The Washburn Chair Professor of International Business and Marketing Fox School of Business, Temple University 1801 Liacouras Walk, Philadelphia, PA 19122-6083, U.S.A.

E-mail: mkotabe@temple.edu

Tel: $\quad 215-204-7704$
\end{abstract}

April, 2021

* corresponding author

(Note: Please do not circulate or cite without the permission of the authors.) 


\section{The Vulnerability Problem of Business Ecosystems under Global Decoupling}

Current dialogue on de-globalization and global decoupling is pervasive but seems to focus merely on the reasoning behind the phenomenon from the perspectives of geopolitical and international relations, such as protectionism, technological nationalism, and the varieties of capitalism. Advancing this dialogue in international business (IB), we focus on the vulnerability problem of multinational enterprises (MNEs) under global decoupling. This commentary aims to improve MNEs' ability to adapt to challenging exogenous shocks (i.e., de-globalization movements as an exogenously occurring event that can affect MNEs' business globally but cannot be resolved by their management and activities). Assuming that global decoupling occurs as an intermittently adjusting process in the transitioning period after a challenging shock, we adopt multi-layered thinking to discuss what salient contexts can exacerbate global decoupling and how MNEs can resolve the vulnerability problem of operating loosely coupled systems. For example, personal protective equipment products have been manufactured through optimal global value chains. But the global shortage of these products shows evidence that international lockdowns since the COVID-19 pandemic have negatively affected the functioning of loosely coupled ecosystems. So, how can MNEs' globally operating business ecosystems adapt to unprecedented global decoupling? Answering it helps IB scholars to take account of different factors and associated business patterns regarding the loosely coupled governance structures of MNEs that pursue resilience under global decoupling.

\section{THE MULTI-LAYERED VIEW ON GLOBAL DECOUPLING}

To address the question, we suggest the multi-layered view, including a macroeconomic level, a firm-level, and an individual level. At each of the three contextual levels, we address the reasoning behind the vulnerability problem of loosely coupled business ecosystems under global 
decoupling and suggest implications for MNEs, which we organize as follows: (1) why global decoupling can be exacerbated, (2) how global decoupling affects loosely coupled business ecosystems, and (3) implications for MNEs' global strategies.

\section{Why Global Decoupling can be Exacerbated}

Since World War II, the world economy couched with network structures has changed substantially over time. First, Cold War tensions between the Soviet Union and the United States separated the economies of their respective allies as the two centralized network structures (see

Figure 1a). Second, the post-Cold War global economic growth era saw the establishment of various regional trading blocs, such as the European Union, the North American Free Trade Agreement, and the Association of Southeast Asian Nations, creating a decentralized network structure (see Figure 1b). Finally, since the dawn of the $21^{\text {st }}$ century, we have started seeing free trade agreements extended beyond regions, such as the EU-Japan Economic Partnership Agreement, the U.S.-Korea Free Trade Agreement, and the Regional Comprehensive Economic Partnership (RCEP), characterizing a more distributed network structure (see Figure 1c).

INSERT FIGURE 1 HERE

With these nontrivial changes at the macroeconomic level, the world economy is observed to be distributed in different regions and countries, resulting in a global decoupling. According to the World Bank's (2020) analysis on world economies based on purchasing power parity (PPP), the PPP-based GDP's regional portions have become similar to each other (see Figure 2). This means that global economies have become relatively distributed economies (i.e., globally scattered demand and supply). More apparently, as shown in Figure 3, variance among the regional portions of the PPP-based GDP has continuously decreased. As the developing 
countries achieve their own economic development through economic and technological upgrading, their unilateral dependencies on developed countries, characterized by a classic centralized network structure, have decreased. Instead, multilateral interdependencies across countries seem to be more plausible in the distributed economies as global markets are further extended.

INSERT FIGURE 2 and 3 HERE

Another significant cause of the global decoupling, at the firm-level, is the emergence of global platform-based business models, such as Airbnb, Uber, Tencent, and Alibaba. Such platform-providing focal firms catalyze the emergence of product ecosystems and motivate customers to consume the focal firm's products and complementary goods from individual complementary partners (Jacobides, Cennamo, \& Gawer, 2018). While traditional business models emphasize investing in local assets to take advantage of supply-side advantages, such as high-tech in developed countries and cheap labor markets in developing countries, platformbased business models encourage firms to reduce direct investment in assets and increase intangible efforts for complementarity among partners. This open system of platform-based business models can lead to global decoupling trends in terms of not requiring as much FDI investment across different countries as under the traditional MNE model that connects foreign subsidiaries hierarchically.

In the globally dispersed economy, ruthless competition at the individual level unavoidably ignites individuals' negative attitude toward globalization, resulting in populism, which has been seen in many democratic countries. In particular, globalization's negative shock has caused economic dislocation and led politicians to pursue populist ideologies and policies for 
better electoral results. From this political science perspective, recent global decoupling can be seen as a manifestation of the accumulated frustrations of people who have been adversely affected by the governments of developed countries that incessantly seek freer trade, and freer mobility of money and labor. Those people with low education levels and low skill sets in the developed countries are vulnerable to global job markets because of the lack of competitiveness compared to those in the emerging economies, including China and India. Since they did not have much political say, politicians have ignored their negative situations during rapid globalization periods. However, recent politicians have paid attention to this underclass with their populistic messages, such as anti-free trade and anti-immigration. Also, these populistic programs can be reinforced by social identity like cultural and racial attitudes. Thus, the appeals of the populists to the working class that wants to recover their low-skilled jobs in developed countries have provoked global decoupling like Brexit and protectionism.

\section{How Global Decoupling Can Affect Loosely Coupled Business Ecosystems}

At the macroeconomic level, distributed economies lead to dispersed technological knowledge and heterogeneous preferences in different markets (Hayek, 1945). As shown in Figure 1c, the distributed economies have a complex network structure where almost all nodes connect each other. For example, Australia, Korea, Japan, and Mexico remain supporters of globalization and open economy (e.g., RCEP) for their export-based models and increase multilateral agreements across different regions. This type of network could have the problem of network congestion due to too many different agreements, which may increase the possibility of network destruction when huge external shocks occur beyond the threshold of multilateral interdependencies, that is, the extent to which each node cannot coordinate its agreements (Balsa-Barreiro, et al., 2020). While the problem of vulnerability in both centralized systems and decentralized systems are associated with 
the capacity of the center and sub-centers to adapt to external shocks, the vulnerability of distributed systems hinges on the degree of network congestion. For example, the European Central Bank, as a sub-center of the global banking system, failed to resolve the Greek public debt crisis in 2009 and caused harmful side effects in other eurozone countries such as Italy and Spain, which implies that absorbing the financial crisis shocks relied upon the roles of the sub-centers of the decentralized network. However, the distributed economies, such as multilateral agreements with plural FTAs, can be vulnerable to external shocks due to excessive interdependencies that cause network congestion and difficulty in coordinating dispersed knowledge and different interests. For instance, the complex multilateral relationships between financial institutions led to the burst of real estate in the U.S. resulting in the global financial crisis in 2008. The excessive risk-taking in the U.S. banks and other financial institutions has been contagious in the world, but each institution failed to resolve the network congestion by itself. Only the bankruptcy or default among financial institutions reduced the excessive links.

At the firm-level, in the business trends of platformization (i.e., business models using common platforms to bridge transactions between two or multiple parties as two-sided markets, for example, eBay and Uber), focal firms tend to reduce ownership-based authority over external partners and shift their organizational governance from ownership-based systems to platformbased systems without ownership (Jacobides et al., 2018). This platformization facilitates autonomous and open systems enabling efficient extensions. As it is not possible to use traditional hierarchical mechanisms such as exclusive contracts, acquisitions, and other equity-based alliances, it would be necessary for MNEs to invent a new control mechanism for their organizations to build ecosystems with autonomous partners. However, if platform companies use their brokerage position as a market-dominating power, a backlash against this monopolistic status can lead to 
global decoupling. The conflicts between EU lawmakers and American platform-based technology companies, such as Facebook, Google, Apple, and Amazon, exemplify.

At the individual level, although many developing countries continue to support globalization for their economic growth through international trade and global value chains, global decoupling in some developed countries can hamper the loosely coupled activities of MNEs from developing countries. Hence, the real challenge can be different between MNEs from developed countries and MNEs from developing countries: (1) how developed-country MNEs cater to global consumer needs by not creating additional ire from now-protectionist politicians at home, and (2) how developing-country MNEs cater to global (especially developed-country) markets by not creating ire from now-protectionist developed countries.

\section{Implications for MNEs' Global Strategies}

At the macroeconomic level, it would be necessary for MNEs to consider a new way of integrating the dispersed knowledge (e.g., technology, experience, and interests) across different times and places in these distributed economies. One possible solution is an ecosystem-based approach to managing this complexity. The ecosystem approach includes not only the type of two-sided markets (i.e., the focal firm's platformization) but the type of industry clusters that include all possible stakeholders to operate MNEs' activities. When penetrating foreign markets, MNEs may consider nurturing local ecosystems to integrate dispersed knowledge by using ecosystem-specific advantages, such as complementarity, positive externalities, and aligning rules of autonomous actors, to manage value co-creation among ecosystem participants (Jacobides et al., 2018). For example, ARM, a semiconductor intellectual property (IP) upstream provider, entered a Chinese market in 2001, when there was no existing market for ARM's IP. But ARM could eventually succeed in China with a business ecosystem through which nurturing 
complementary partners and enabling lead partners to coordinate complementary partners autonomously. This business ecosystem approach allows many firms to integrate dispersed knowledge autonomously through complex interactions.

At the firm-level, to avoid the risk of global decoupling, MNEs' operating platform businesses in foreign markets may need to consider self-organizing ecosystems to attract autonomous participation without using tangible powers (i.e., brokerage powers, reputations, and other market leader status). Self-organizing ecosystems are based on the mechanisms of facilitating positive feedback loops by network effects and co-evolution between the platform leader and participants. For example, innovation clusters exemplify self-organized business ecosystems through positive feedback loops of sharing resources and knowledge spillover. As such, these MNEs should build up competence to design and manage their common platform enabling so-called virtual agglomeration effects within the business ecosystems.

Furthermore, MNEs must intensify resilient and adaptive capabilities quickly to respond to the populistic backlash against their global activities that could cause the potential risks of economic dislocation at the individual level. In that, they may need to reconsider boosting up the local economy for their sustainable business in the host countries. For instance, many large Asian companies with enough resources have established factories close to customers in the U.S. to meet the demands and avoid populistic policies and uncertainty. Foxconn's plan to investing in a display panel manufacturing plant in Wisconsin exemplifies this effort to avoid a populistic backlash. The organizational agility of MNEs to reallocate complementary assets within the business ecosystems could be an essential factor in the context of global decoupling.

In short, MNEs are able to reconsider these issues of dispersed knowledge, platform design, and organizational agility to solve the vulnerable problems under global decoupling. 


\section{CONCLUSION}

In this commentary, we adopt multi-layered thinking to systematically analyze the causes and effects of global decoupling that creates potential vulnerability problems for the MNEs operating with loosely coupled business ecosystems. Then, we further offer several feasible solutions for these MNEs to effectively respond to the challenging shock. Such an approach contributes to the IB literature by advancing the existing knowledge of governance and control mechanisms for MNEs operating with loosely coupled systems in the context of global decoupling and, equally importantly, by providing concrete implications for global strategies. This multi-layered view

provides a useful steppingstone for the scholars from IB, management, and other fields as they make further efforts to understand other related, important questions (e.g., how global value chains adapt to global decoupling) and conduct empirical investigations, all of which are indispensable for continuing the present dialogue on global decoupling and beyond. 


\section{REFERENCES}

Balsa-Barreiro, J., Vié, A., Morales, A. J., \& Cebrián, M. 2020. Deglobalization in a hyperconnected world. Palgrave Communications, 6(1): 1-4.

Hayek, F. A. 1945. The use of knowledge in society. American Economic Review, 35(4): 519530.

Jacobides, M. G., Cennamo, C., \& Gawer, A. 2018. Towards a theory of ecosystems. Strategic Management Journal, 39(8): 2255-2276.

World Bank. 2020. Purchasing Power Parities and the Size of World Economies: Results from the 2017 International Comparison Program. 
Figure 1

The Evolution of Economic Network Structures

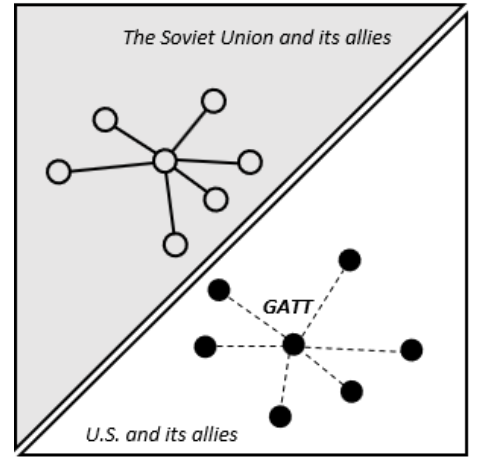

(a) Centralized structure

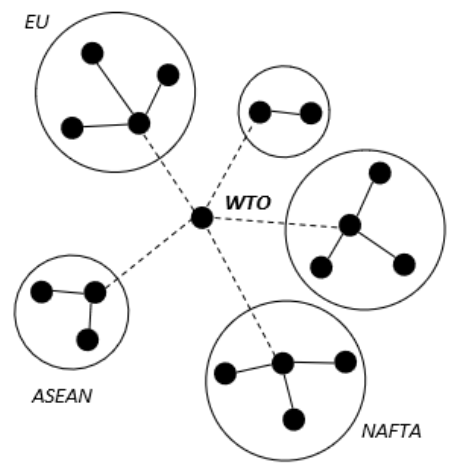

(b) Decentralized structure

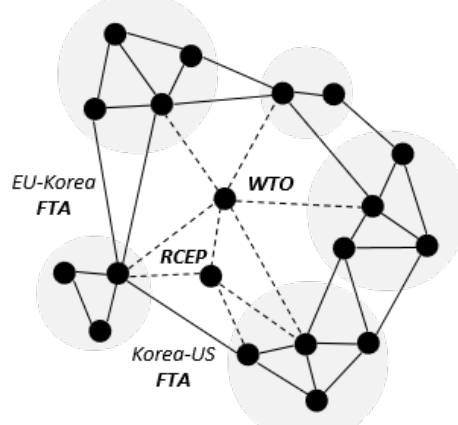

(c) Distributed structure

Note: A solid line represents a tightly coupled relationship between countries with specific agreements. The dashed line depicts the loosely coupled relationship between international institutions (i.e., GATT and WTO) and their member countries. 
Figure 2

Changes in Regional Portions of World Economies

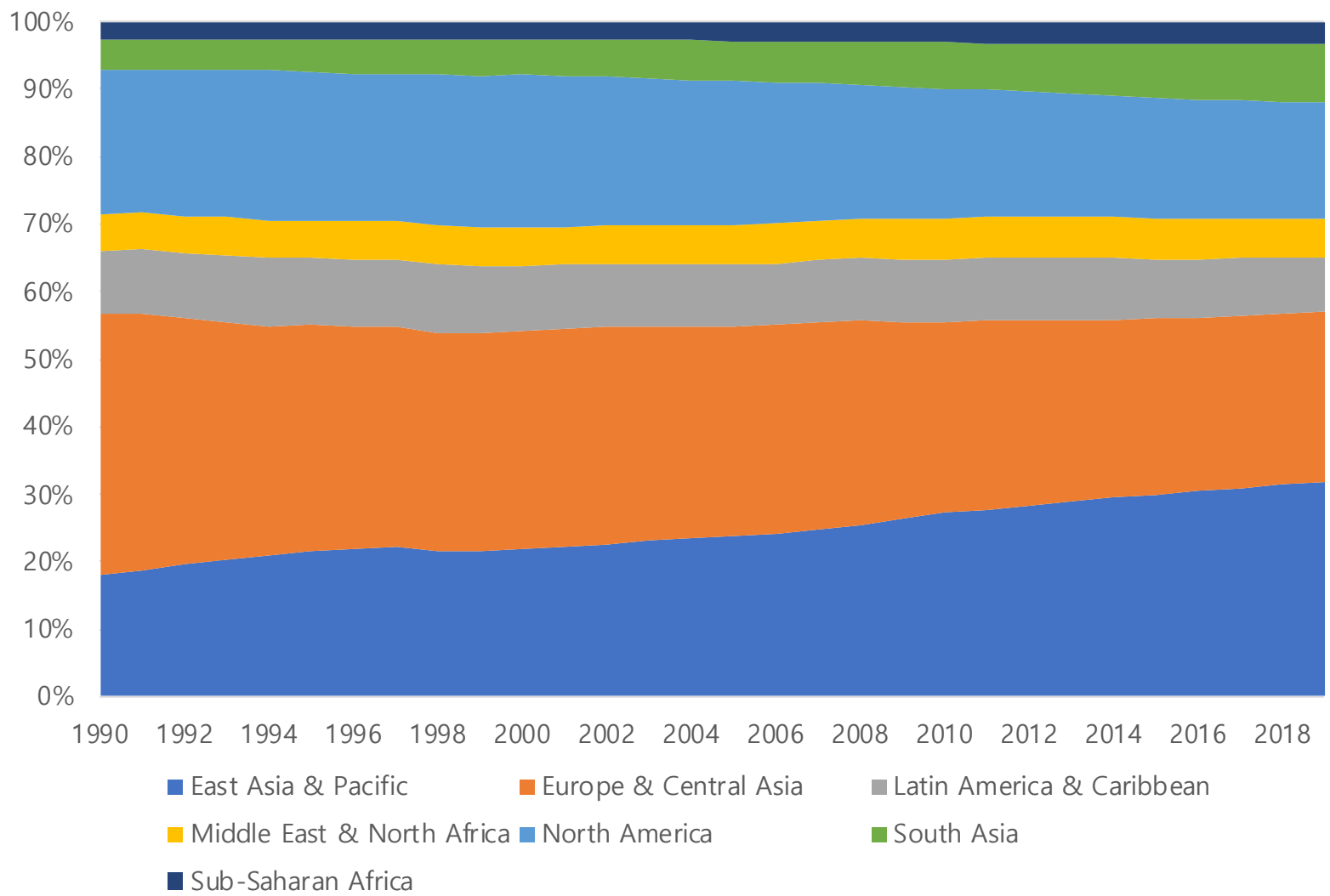

Source: World Bank (2020). 
Figure 3

\section{The Variance of Regional Portions of World Economies}

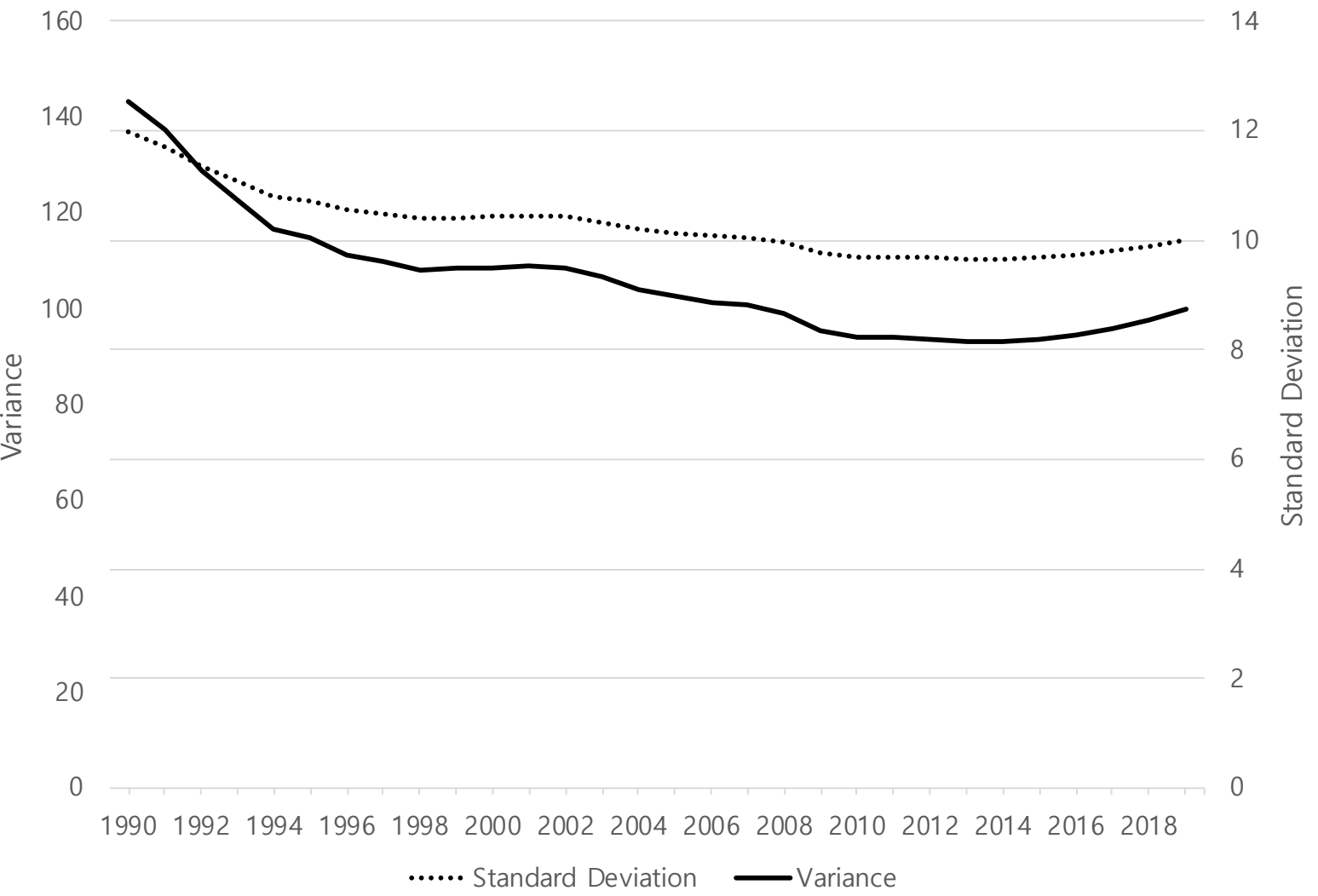

Note: The reduced trends of variance and standard deviation imply differences in the size of economies by region are decreasing. But the rapid increases in 2019 could be associated with the difference by region in national policies to block economic activities in response to the Covid-19 pandemic. Source: World Bank (2020). 